come after single-lung transplantation. Ann Thorac Surg 1994; $58: 1336-42$.

2. Gammie JS, Keenan RJ, Pham SM, McGrath MF, Hattler BG, Khoshbin E, et al. Single- versus double-lung transplantation for pulmonary hypertension. J Thorac Cardiovasc Surg 1998;115: 397-403.

3. Pasque MK, Trulock EP, Cooper JD, et al. Single lung transplantation for pulmonary hypertension. single institution experience in 34 patıents Circulation 1995:92:2252-8.

$12 / 8 / 93652$

Histologic grading: A, B, C or 1, 2, 3?

To the Editor:

Mr Lee and colleagues from Dr Shennib's group are to be congratulated for an interesting and provocative study ( $\mathbf{J}$ Thorac Cardiovasc Surg 1998;115:822-7) that supports their hypothesis that bronchiolitis obliterans is not related just to chronic rejection in lung allografts. Using activated charcoal as an airway irritant. the authors demonstrated that either an irritant alone or reduced immunosuppression after transplantation resulted in mild bronchiolitis. but the combination of arway irritant and reduced immunosuppression produced more impressive histologic findings consistent with obliterative bronchiolitis.

However. I take issue with the calculation of mean grades of airway injury using a grading system that arbitrarily assigns numbers to histologic patterns of injury. If the histologic categories were labeled A, B, C, and D instead of 1,2, 3 , and 4 , what would be the mean of $2 \mathrm{~A}$ 's and $3 \mathrm{C}$ 's? It would be statistically appropriate to compare the groups by looking at the distribution of scores within each group, rather than calculating a mean from data that are not arithmetic. Although this is common practice with histologic grades, it is mathematically inappropriate. Unfortunately, the need for nonparametric analysis translates into a requirement for a much larger number of animals to establish statistical significance to the observation. This criticism is not meant to detract from the elegance of the experiment but only to raise the point that not all observations need to be "statistically significant" before they are relevant. Perhaps the authors could share the distribution of scores, rather than the mean scores.

Thomas M. Egan, MD

Professor

Associate Division Chief for General Thoractc Surgery Department of Surgery University of North Carolina at Chapel Hill 108 Burnett-Womack Building

$C B 7065$

Chapel Hill, NC 27599-7065

$12 / 8 / 94225$

Reply to the Editor:

The comment made by Dr Thomas Egan is well taken. Grading the severity of airway injury by nonparametric analysis requires an extensive number of animals, which we could not determine before the experiment. When data were reviewed by classification A. B. C. and D instead of $1,2,3$, and 4 , we found there were $5 \mathrm{~A}$ 's and $3 \mathrm{~B}$ 's in group I (trans- plantation alone), 4 C's and 6 D's in group II (transplantation plus charcoal), and 2 A's, 7 B's, and $1 \mathrm{C}$ in group III (charcoal alone). As such. the data stand to confirm that the combination of transplantation and charcoal transtracheal injection result in more pronounced injury to the airway.

Hani Shennib, MD

Associate Professor

Department of Cardiothoracic Surgery

Adel Giaid, $M D$

Associate Professor

Department of Pathology

Mc Gill University

Montreal, Quebec, Canada

$12 / 8 / 94226$

\section{Multiple primary lung carcinomas}

\section{To the Editor:}

The report by Okada and colleagues ${ }^{1}$ highlights the treatment options and survival statistics that are appropriate for patients with multıple primary lung carcinomas (MPLCs), but we think some further points need to be discussed.

In a recent article by Antakli and colleagues, ${ }^{2}$ a set of criterı modified from Martini and Melamed ${ }^{3}$ has been applied to differentiate MPLCs and recurrence of satellite nodules. In addition to those mentioned by Okada and associates, associated premalignant lesions and different DNA ploidy have been presented as the 2 other criteria in the case of identical histologic type. ${ }^{2}$ When Martini and Melamed's criteria were not conclusive, they advocated DNA ploidy to provide a definite answer to this dilemma. However, Okada and colleagues have not suggested using the ploidy issue for patients with MPLCs.

We performed left pneumonectomy for a 60 -year-old man who was operated on for squamous cell carcinoma of the lung (T2 N1 M0, grade III). One year after the operation, a nodule with a $2.5-\mathrm{cm}$ diameter located in the right upper lobe was detected by both chest roentgenography and chest computed tomography. Segmentectomy was performed, and the histologic type of this tumor was the same as that of the first one (T2 N0 M0, grade III). We considered this tumor to be a second primary lung cancer, because the tumor was anatomically separate and did not have any systemic metastases or mediastinal spread. On the other hand, although the number of criteria that had to be met in the case of identical histologic type was sufficient, we used the ploidy issue in our patient. Even though the histologic features were the same in all of the lesions, the DNA ploidy signatures differed.

Although lung-saving procedures for a primary lesion are advocated in the article. ${ }^{1}$ the risk of having MPLCs after pneumonectomy is significantly lower than after lobectomies or miniresections. ${ }^{2}$

Another point is the striking prevalence of smoking among the patients with MPLCs and the preventive effect of cessation that has been demonstrated by many authors. ${ }^{2,4}$ Do Okada and associates have any information about the prevalence of smoking among their patients?

From the historical point of view, we would like to know 